\title{
De las reformas a la revolución postergada: la historia de El Salvador en el siglo XX
}

\section{Carlos Gregorio López Bernal'}

Recepción: 6 de enero de 2017 / Aprobación: 23 de marzo de 2017

\section{Resumen}

El artículo hace un estudio de la historia política de El Salvador en el siglo XX desde la perspectiva de los procesos de reforma impulsados a lo largo de la centuria y propone que la postergación o el bloqueo de las reformas ha sido una constante histórica. Se analizan algunos factores necesarios a tomar en cuenta para un estudio más profundo: el grado de elaboración y los objetivos del proyecto reformista, los costos económicos de la implementación, la influencia externa, y los apoyos y oposiciones internas. La postergación de las reformas conllevó al aumento de las dificultades para implementarlas. En la década de 1970, la postergación y bloqueo de las reformas radicalizó a la oposición política; aún así, en 1979 se impulsó un ambicioso proyecto reformista que fue combatido tenazmente por la derecha, que por primera vez era seriamente afectada en sus intereses económicos y políticos, y por la izquierda, porque las reformas se interponían con su proyecto revolucionario.

\section{Palabras clave}

El Salvador; reforma; revolución; historiografía; militarismo

\section{Abstract}

The article studies the political history of El Salvador in the twentieth century from the perspective of the reform processes promoted throughout the century and proposes that the postponement and / or blocking of reforms has been a historical constant. Some factors should be considered for a deeper study: the degree of elaboration and the objectives of the reform project, the economic costs of implementation, the external influence, and the internal supports and oppositions. The postponement of reforms increased the difficulty of implementing them. In the 1970s, the postponement and blockade of reforms radicalized the political opposition; even so, in 1979 an ambitious reformist project was pushed that was rejected by the right, that for the first time was seriously affected in its economic and political interests, and by the left, because the reforms interposed with its revolutionary project.

\section{Keywords}

El Salvador; reform; revolution; historiography; militarism

1 Salvadoreño. Doctor en Historia por la Universidad de Costa Rica (UCR). Docente-investigador de la Licenciatura en Historia de la Universidad de El Salvador (UES). Correo electrónico: cglopezb@gmail.com 


\section{Resumo}

O artigo faz um estudo da história política de El Salvador no século XX a partir da perspectiva do processo de reforma conduzido ao longo do século e propõe que o adiamento e / ou o bloqueio das reformas tem sido uma constante histórica. Se analise alguns fatores a considerar em um estudo mais profundo: a classe de elaboração e os objetivos do projeto reformista, os custos econômicos da execução, a influência externa, e os apoios e as oposições internas. Adiar as reformas levaram a dificuldades acrescidas na sua execução. Na década de 1970, o atraso e bloqueio de reformas radicalizou oposição política; ainda em 1979 um projeto de reforma ambiciosa que foi combatido tenazmente para a direita, que primeiro foi seriamente afectada nos seus interesses económicos e políticos, e à esquerda, porque as reformas dificultar o seu projeto revolucionário.

\section{Palavras chave}

El Salvador; reforma; revolução; historiografia; militarismo

\section{Antecedentes historiográficos}

Los estudios sobre la historia de El Salvador del siglo XX han logrado importantes avances en las últimas décadas. Sin duda, la tragedia que vivió el país en la década de 1980, hizo que académicos nacionales y extranjeros trataran de encontrar explicaciones a la guerra civil que entonces desangraba al país. Rápidamente los investigadores se dieron cuenta que, para entender qué estaba pasando en esta región, era preciso conocer mejor su historia, a fin de encontrar las raíces del problema. Así fue surgiendo una variada bibliografía que trataba de explicar las causas de la guerra y, aunque ninguna podía obviar que la confrontación este-oeste la marcaba -al menos para justificar posicionamientos ideológicos-, muy pronto se entendió que las causas determinantes y profundas estaban en la sociedad salvadoreña.

Poco a poco se fue construyendo una agenda de trabajo de más largo alcance y, sobre todo, de mayor potencial explicativo. Por ejemplo, quienes vieron en la pobreza y el problema agrario una causal de conflicto, tuvieron que estudiar la conformación histórica de la estructura agraria salvadoreña; hubo que volver al trabajo pionero de David Browning que advirtió del potencial conflictivo de la concentración de la propiedad de la tierra antes de que el problema se agudizara y diera lugar a la crisis (1998).

Rafael Menjívar dio continuidad al problema agrario; a diferencia de Browning, Menjívar venía estudiando el tema por años y, además, estaba directamente involucrado en el proyecto revolucionario de izquierda. Según el pensamiento marxista de la época, la madurez del capitalismo implicaba el agravamiento de sus contradicciones internas, con lo cual, las condiciones para la revolución se volvían más propicias; de allí el sugerente título de su libro: Acumulación originaria 
y desarrollo del capitalismo en El Salvador. La tesis implícita del trabajo era que, para finales de la década de 1970, en El Salvador, existían condiciones para la revolución (Menjívar, 1980)².

Más tarde, aparecieron los trabajos de Héctor Lindo y Aldo Lauria. El primero hizo un estudio de largo aliento sobre la economía de El Salvador en el siglo XIX, lo cual lo llevó a estudiar al añil y el café, así como la extinción de tierras comunales y ejidales. Lindo dio preponderancia en su estudio al papel de las élites en la construcción del Estado y en la reorientación de la economía (Fuentes, 1990). Por su parte, Lauria centró su atención sobre el papel que jugaron indígenas y campesinos en las dinámicas económicas y políticas. A diferencia de sus antecesores, el autor considera que no fue hasta finales de la centuria (1890) que el Estado salvadoreño se consolidó (Lauria Santiago, 1999).

El sistema político de dicho país también atrajo interés. Se daba por sentado el carácter autoritario y poco democrático de los gobiernos que antecedieron a la guerra civil. Sin embargo, esta tendencia política no era novedad; más bien se convirtió en una constante histórica que se manifestaba con mayor o menor intensidad, dependiendo del momento. En realidad, el autoritarismo es parte constitutiva de nuestra cultura política y, por sí solo, no ayuda a explicar el devenir histórico de El Salvador (Guidos Véjar, 1980)³. En esta línea, el trabajo pionero de Ching, en su tesis doctoral, abrió una línea de investigación interesante, la cual demoró bastante en ser publicada (1997; 2013). Este autor concibe al sistema político salvadoreño como una compleja construcción piramidal que se sostiene por la interacción de redes de poder construidas bajo la lógica del patronazgo y el clientelismo. El poder se distribuía jerárquicamente; el status de cada participante dependía de una relación de dominación y subordinación relativas, en la que los jefes locales usaban sus clientelas para afianzar el poder municipal y avanzar hacia el poder regional y de, ser posible, nacional. El denominador común de estas relaciones era el carácter abusivo y autoritario que las permeaba, sin embargo, patrones y clientes terminaban ganando algo; de allí la permanencia del sistema.

Como contraparte y complemento al tema del sistema político y las relaciones de poder, fueron apareciendo estudios sobre los movimientos sociales. La organización popular en las décadas de 1910 y 1920, el levantamiento de 1932, las luchas contra el gobierno de Maximiliano Hernández Martínez o, más recientemente, las

2 Una idea similar subyacía en otro trabajo suyo (Menjívar, 1979). En este caso, Menjívar se esforzó por mostrar un temprano desarrollo de la clase obrera, en tanto que esta era la llamada a hacer la revolución. Pero el país nunca tuvo una industria capaz de generar un proletariado significativo; de allí que la izquierda armada tuviera que virar al campo para construir su base social más sólida, en ese viraje fue crucial el trabajo previo que la Iglesia Católica había hecho entre los campesinos (Chávez, 2010) (Sprenkels, 2014).

3 Para una buena discusión sobre las relaciones entre tierra, café y poder político en El Salvador, véase Paige (1993). 
luchas de los trabajadores y campesinos organizados en las décadas previas a la guerra civil, son algunos de los temas más investigados ${ }^{4}$.

Sin desvalorar la capacidad explicativa de cada uno de estos trabajos, pronto se constató que había cuestiones que seguían sin ser respondidas. Estructura agraria, pobreza o sistema político eran variables ineludibles y su estudio proveía importantes luces sobre la sociedad salvadoreña. No obstante, en la medida en que se profundizaba en ellas, se comprobaba que esas estructuras no habían sido estáticas ni monolíticas. De hecho, los estudios de los movimientos sociales, sin importar cómo se concibieran, mostraban una recurrente demanda de cambios provenientes de diversos sectores sociales y, más importante, esas demandas habían tenido eco en los detentadores del poder o habían coincidido con la agenda de otros actores políticos y sociales dispuestos a impulsarlas. Estas tendencias se hacen evidentes en los estudios sobre la revolución de 1948, los gobiernos del Partido de Conciliación Nacional (PCN) y las reformas ligadas al golpe de Estado de 1979. Es decir, aparece una interesante confluencia de iniciativas impulsadas desde los sectores dominantes "desde arriba", con otras demandadas planteadas, "desde abajo", por sectores populares organizados.

Quizá, sin proponérselo, la historiografía salvadoreña fue develando la importancia de las reformas para entender El Salvador del siglo XX. Después, aparecieron trabajos que trataron casos particulares, los cuales comenzaron a calar en el tema de las reformas, por ejemplo, el iluminador y sugerente estudio de Turcios, Autoritarismo y modernización: El Salvador 1950-1960, publicado por primera vez en 1993 (2003) y la tesis doctoral de Cáceres Prendes, Discursos de reformismo: El Salvador 1944-1960 (1995). En la misma línea podrían incluirse el libro de Almeida, Olas de movilización popular (2011), del cual pueden desprenderse interesantes y provocadoras tesis o, más recientemente, el de Lindo y Ching sobre la reforma educativa durante el gobierno de Sánchez Hernández (2012). Un balance general de estas investigaciones daría pistas suficientes para entender la importancia de los proyectos reformistas en la historia salvadoreña del siglo XX pero, sobre todo, mostraría la necesidad de hacer un estudio de largo aliento sobre esta problemática. Por hoy, simplemente se adelantan algunas ideas, producto de la revisión de la historiografía más relevante y de la reflexión provocada por tales obras.

\section{Los proyectos de reforma}

A lo largo del siglo XX, El Salvador vivió al menos cinco proyectos de reforma. Algunos fueron truncados cuando apenas iniciaban, por ejemplo, el impulsado por Manuel Enrique Araujo (1911-1913), o el poco estudiado -y aún menos comprendido- de Pío Romero Bosque (1927-1931). El primero se frustró

4 Entre ellos destacan Alvarenga (1996), González Márquez (2016), Anderson (1982), Ching, López Bernal y Tilley (2007), Parkmam (2003), Cabarrús (1983) y Kincaid (1987). En esta línea de trabajo destaca sobre manera la tesis doctoral de Chávez M. (2010). 
por el asesinato del presidente Araujo en 1913; el segundo, fue ahogado por la crisis económica y social que desembocó en la matanza de 1932. Otros proyectos lograron tal grado de coherencia en su formulación y tales avances en su implementación que dejaron profundas huellas en la sociedad; tal es el caso de los impulsados durante las décadas de 1950 y 1960, herederos de la "Revolución del 48". En realidad, son dos momentos de reforma que pueden verse como partes complementarias y consecutivas de un gran proyecto modernizador que inició en 1948. O, más importante -al menos por las trágicas implicaciones de su fracaso-, fue el impulsado en 1979 por una alianza de militares y civiles, en un desesperado intento por evitar la inminente guerra civil.

A este listado podrían agregarse las reformas impulsadas por Maximiliano Hernández Martínez en la década de 1930 y las implementadas después de los Acuerdos de Paz de 1992, pero sus peculiaridades dificultan incluirlas en el presente trabajo. Las primeras, porque no provenían de un proyecto plenamente articulado, sino de la necesidad de enfrentar una crisis que había llevado a la tragedia de 1932; en realidad, eran cambios que solo trataban de revitalizar la república cafetalera liberal luego de la crisis económica de 1929 y el levantamiento de 1932. Las otras, porque se limitaron a cambios políticos e institucionales, pero no consideraron reformas económicas; por el contrario, en la década de 1990, aún después del Acuerdo de Paz, los gobiernos de derecha continuaron implementando políticas neoliberales que condujeron a la desaparición o privatización de diferentes instituciones estatales, algunas de ellas, herencia de las reformas de los años cincuenta del siglo pasado.

Es decir, posterior a 1992, el país vivió, de forma simultánea, dos procesos de reforma: uno, nacido del Acuerdo de paz, orientado a modernizar y democratizar el sistema político, y otro heredero del "consenso de Washington", que apuntaba a la disminución del Estado y que revirtió o bloqueó importantes reformas impulsadas en la década anterior, específicamente la nacionalización de la banca, del comercio exterior y la reforma agraria. Esa condición vuelve difícil incorporar las reformas pos Acuerdo de paz en el marco de análisis de este trabajo.

Lo planteado hasta aquí justifica dedicarle más atención a los proyectos de reforma, los cuales han sido vistos de forma peyorativa en tanto se asocian con acciones contrarrevolucionarias; es decir, se hacen reformas para evitar las revoluciones. Es muy sugerente que el Diccionario de Política de Bobbio dedica muchas páginas a discutir el concepto de "revolución", pero no contiene el de "reforma". Sin embargo, habla de "reformismo", entendido como un "movimiento que apunta a mejorar y perfeccionar, tal vez radicalmente, pero no a destruir el ordenamiento existente"; lo asocia con actores políticos que optan por "la vía gradual y pacífica" (Bobbio, Matteucci y Pasquino, 1978, p. 1358). No obstante, en la ambigüedad de la definición, queda claro que la reforma busca modificar una situación con miras a mejorarla, llegando incluso a cambios radicales. Vale decir que las reformas no están amarradas a actores políticos 
o ideologías ya que, a menudo, sus impulsores son militares de tendencias modernizantes, pero de pensamiento anticomunista (Lindo Fuentes y Ching, 2012) ${ }^{5}$. Debido a la complejidad del tema, es preciso acotar el abordaje. A fin de dar un hilo conductor al análisis se considerarán en su orden: el grado de elaboración y el alcance de los objetivos de las reformas; la demanda de recursos para financiamiento del proyecto; la influencia externa, en tanto coadyuve o dificulte el proceso y, por último, los apoyos y oposiciones internas que el proyecto de reforma genere.

\section{Nivel de elaboración y alcances de los proyectos}

Resulta importante señalar que los niveles de elaboración de los proyectos de reforma y los objetivos que perseguían variaron significativamente. A falta de mejores investigaciones, pareciera que, en los casos de Manuel Enrique Araujo y Pío Romero Bosque, primó una determinación de tipo individual. En el primer caso, se hicieron cambios en la legislación laboral para favorecer a los trabajadores y se comenzó a tratar el tema fiscal. En el segundo, se ampliaron las libertades políticas y de organización; se legisló sobre lo laboral, pero favoreciendo solo a los trabajadores urbanos. Ambos presidentes tenían preocupaciones humanistas y de corte social, amén de un fuerte carácter que les permitió impulsar su agenda reformista a pesar de las fuertes resistencias que encontraron. No obstante, ninguno pretendió transformaciones que fueran más allá de mejorar las condiciones de vida de la población más necesitada por medio de cambios puntuales a la legislación. El personalismo que impregnaba las reformas hizo que, una vez desaparecidos sus impulsores, estas se estancaran o, incluso, se revirtieran ${ }^{6}$.

Por el contrario, las reformas de las décadas de 1950 y 1960 fueron producto de una preocupación compartida por importantes grupos de militares y civiles, incluyendo empresarios, cuyo objetivo general era un proyecto de desarrollo nacional enmarcado en una visión de modernización de la economía y democratización del sistema político, el cual fue cobijado en la constitución de 1950 -la más progresista y de más hondo contenido social que ha tenido el país- y que hacía del Estado el principal promotor del desarrollo económico, a la vez que sentaba las bases de los principios de justicia social, aplicándolos al régimen económico?

Se impulsó un ambicioso programa de reformas, orientado a la integración económica regional que luego daría lugar a la conformación del Mercado

\footnotetext{
5 Generalmente, a las reformas se contrapone la revolución, en tanto esta busca cambios radicales en los diferentes ámbitos de la sociedad (Torres, 2013).

6 Véase Chasteen (1984); Paredes (1930), Wilson (2004), López Bernal (2000) y Molina (2015).

7 Véase Turcios (2003).
} 
Común Centroamericano (MERCOMUN) y a fortalecer la economía nacional a través de la industrialización por sustitución de importaciones, así como la diversificación de la agricultura de exportación. De forma paralela, se crearon instituciones orientadas a impulsar las primeras políticas sociales de Estado realmente funcionales en la historia nacional, por ejemplo, el Instituto Salvadoreño del Seguro Social (ISSS), el Instituto de Vivienda Urbana (IVU) y el Instituto de Colonización Rural (ICR).

Este proyecto de desarrollo no surgió de una crisis. Por el contrario, la década de 1950 fue de bonanza económica; en 1950, el café valía 132.6 colones, mientras que para 1954 había alcanzado la suma de 171.1 (PNUD, 2013b, p. 78). Más bien, se trató de aprovechar una coyuntura económica para fortalecer la economía mediante la modernización y la diversificación de la inversión.

En septiembre de 1950 se creó un impuesto de carácter progresivo sobre la exportación de café, en donde el monto variaba según los precios del grano; un año después, se modificó el impuesto sobre la renta con una lógica progresiva, dando un tratamiento favorable a la industria y a las sociedades anónimas (Turcios, 2003, pp. 82-83). Los resultados se vieron de inmediato y para 1949 los impuestos del gobierno central eran de 64.04 millones de colones, alcanzando 156.9 millones para 1954 (Dada Hirezi, 1978, p. 39). Resulta claro que hubo oposición de los capitalistas, pero el gobierno manejó bien la situación; justificó debidamente la medida, hizo ver los beneficios que de ella se derivaban y, cuando fue necesario, impuso su autoridad.

Empero, los beneficios para los sectores sociales subalternos fueron dispares. Los salarios no subieron, sin embargo, al mejorar la recaudación de impuestos, el Estado impulsó sus políticas sociales, mejorando indirectamente las condiciones de vida de los trabajadores. En general, se favoreció más a los trabajadores urbanos y se marginó a los rurales. Al final de cuentas, la diversificación de la agricultura de exportación tuvo un costo social muy alto. El algodón, la caña de azúcar y la ganadería incorporaron a la dinámica productiva tierras que, hasta entonces, habían estado sin uso o dedicadas a la agricultura de subsistencia. Además, tampoco se aumentaron los niveles de empleo. Campesinos y jornaleros buscaron otras opciones: cultivar tierras menos fértiles, emigrar a las ciudades sin tener la formación necesaria para insertarse en el mundo laboral, o emigrar a Honduras. Para inicios de la década de 1970, estas alternativas se habían agotado.

No obstante, a pesar de dichas falencias, la economía tuvo sus mejores años de crecimiento y las políticas sociales del Estado alcanzaron a sectores sociales hasta entonces marginados. El gasto en desarrollo humano subió del $15 \%$ a más del $35 \%$. En consecuencia, 
entre 1950 y 1975, la esperanza de vida al nacer aumentó de 45 a 60 años, la tasa de mortalidad general disminuyó de 20.6 a 11.5 por cada mil habitantes y la tasa de mortalidad infantil de 81 a 60 por cada 1000 nacidos vivos ... la tasa bruta de matriculación primaria aumentó de 41\% a 88\% (PNUD, 2013a, p. 83).

También, el proyecto reformista de 1979 fue muy ambicioso; basta con revisar la "Proclama de la Fuerza Armada" del 15 de octubre de 1979 para caer en la cuenta de la magnitud de los cambios que se trataba impulsar. $\mathrm{Ni}$ el Acuerdo de Paz de 1992, ni ninguno de los planes de gobierno de derecha o de izquierda de la postguerra, pretendieron transformaciones tan profundas como las de 1979; estas no se quedaron en simples propuestas, sino que fueron realizadas. De allí que surja la duda si, en este caso, se trata de una reforma o, más bien, de una ruptura. La profundidad de los cambios impulsados y la extrema polarización política-ideológica que los acompañó inducen a remarcar la ruptura. Sin embargo, los efectos de las medidas fueron atemperados por la guerra civil misma, pero también por la reversión y ahogamiento de las reformas que implementó el partido de ARENA, una vez que llegó al poder en 1989.

Los componentes más importantes de las reformas de 1979 son: reforma agraria, nacionalización de la banca y nacionalización del comercio exterior, amén de otras de corte social que apuntaban a mejorar las condiciones de vida de los sectores populares y frenar el alto costo de la vida. A diferencia del proyecto surgido de la revolución del 48, las reformas de 1979 estaban condicionadas por la crisis que el país vivía; por lo tanto, fueron orientadas a resolver, de urgencia, los graves problemas, al borde de la guerra civil. Para empeorar las cosas, su implementación se dio ya en plena guerra civil, con lo cual se desnaturalizaron y perdieron legitimidad. No extraña entonces que su ejecución fuera obstaculizada por ambas extremas. La derecha vio en la amplitud y profundidad de las reformas un claro atentado contra sus intereses económicos y un indicador elocuente de la penetración izquierdista en la Junta de Gobierno. La izquierda, por su parte, primero cuestionó las reformas y luego las rechazó, hasta calificarlas de simples medidas contrainsurgentes (Walter Franklin, 2001b).

En realidad, la izquierda -para entonces aglutinada en el Frente Farabundo Martí para la Liberación Nacional (FMLN) y el Frente Democrático Revolucionario (FDR) - compartía parte de la agenda de cambios que impulsaban los militares: reforma agraria, la nacionalización de la banca y el comercio exterior. La "Plataforma programática" del FMLN- FDR de finales de 1980, además del gran objetivo de hacer una "revolución popular, democrática y antiimperialista", incluía las reformas antes apuntadas (Martín Álvarez, 2004, p. 190). La izquierda radical se oponía a las reformas porque le quitaban banderas en un momento en que el triunfo revolucionario parecía estar al alcance de la mano. Sin embargo, mantuvo tales propuestas incluso en 1984, cuando se presentó la "Plataforma de gobierno de amplia participación", y en la "Proclama de la revolución democrática" de septiembre de 1990 (Martín Álvarez, 2004, p. 196 y p. 202); por lo tanto, no eran accesorias ni coyunturales. Curiosamente, el FMLN de la posguerra dio por 
cerrado ese capítulo, sin haber discutido -al menos no de forma abierta- hasta qué punto se habían superado los problemas socioeconómicos que las reformas de 1979 pretendían atacar y, de ser necesario, explicar cómo se resolvieron, al grado de que ya no sea necesario incluirlos en sus propuestas de gobierno.

\section{Financiamiento e influencia externa}

El segundo componente a tomar en cuenta es el financiamiento en el que, a falta de estudios puntuales y, sobre todo, datos cuantitativos, apenas se esbozarán un par de consideraciones. Hay que señalar que la demanda de financiamiento depende de la magnitud de los cambios que se pretenda ejecutar. Casos como los ya apuntados de Araujo y Romero Bosque no requerían mayores recursos económicos; por el contrario, las reformas de las décadas de 1950 y 1960 y las que siguieron al golpe de Estado de 1979 necesitaban de fuerte financiamiento. Un programa amplio de reformas demanda ingentes recursos. Para evitar ese conflicto solo quedan dos caminos: cooperación externa, que depende mucho del tipo de reforma a impulsar, del momento y de quién solicite la ayuda; o mayor recaudación fiscal, la cual solo es posible si la economía nacional pasa por un buen momento, de tal modo que la resistencia del capital sea menor.

Tal confluencia de condiciones solo se dio durante las décadas de 1950 y 1960. En el primer decenio, los buenos precios de los productos de agroexportación -sobre todo, café y algodón- generaron recursos extraordinarios, algunos de los cuales fueron invertidos en la industria; el Estado aprovechó esa feliz circunstancia y elevó la recaudación fiscal aumentando los impuestos a las exportaciones y la renta. Según Héctor Dada, el producto del impuesto sobre las exportaciones pasó de 4.5 millones de colones en 1946, a 46.24 millones en 1954. Para el último año este impuesto representaba el $29.7 \%$ del total recaudado. Los ingresos del Estado se elevaron de 36.72 millones de colones en 1946, a 156.9 en 1954 (Dada Hirezi, 1978, p. 39) (Bulmer Thomas, 1989, p. 159). En la segunda mitad del decenio, el país comenzó a ver los beneficios de la incipiente industrialización en el marco del MERCOMUN, una iniciativa de corte cepalino que se venía impulsando desde años atrás. Cooperación externa y buenos precios de los productos de exportación permitieron contar con mayores recursos sin tensar en demasía las relaciones con el gran capital (Walter Franklin, 2001a, pp. 489-490).

Otro elemento a considerar es la influencia externa, entendida no tanto como cooperación económica, sino como estímulo y asesoría a los procesos de reforma. Aunque es claro que en todos los casos la decisión de realizar reformas provino de actores nacionales, en algunos, el contexto internacional y la acción externa fueron factores importantes. La influencia externa fue inexistente o muy marginal en los procesos de reforma de las primeras décadas del siglo, pero se volvió un factor coadyuvante en los procesos de los años 
comprendidos entre 1950 y 1960, sobre todo en este último periodo, cuando las iniciativas reformistas de los militares y el recién creado Partido de Conciliación Nacional encontraron un contexto internacional favorable e importantes socios en instancias como la Alianza Para el Progreso, la Alianza de los Estados Unidos para el Desarrollo Internacional (US-AID) y la Organización de las Naciones Unidas para la Educación, la Ciencia y la Cultura (UNESCO), amén de un contexto regional integracionista que favorecía la vertiente industrializante de las reformas (Lindo Fuentes y Ching, 2012, pp. 105-120). Con motivaciones diferentes, desde el sur, el pensamiento de la CEPAL, también estimulaba los esfuerzos de transformación de las economías latinoamericanas ${ }^{8}$.

En el caso de 1979 hubo una fuerte participación de los Estados Unidos en la implementación de las reformas, especialmente en la agraria; ese involucramiento dio argumentos a los opositores de derecha e izquierda para rechazarlas. En este punto, los opuestos se encuentran: la derecha vio en el apoyo estadounidense la confirmación de que enfrentaban una doble conspiración imperialista, ya que, por una parte, los Estados Unidos -en su afán de quitar banderas a la izquierda insurgente- no dudaba en sacrificar a sus, hasta hacía poco, aliados nacionales, y, por otra, al comunismo internacional, que no renunciaba a su vocación expansionista9 ${ }^{9}$. Por su parte, para la izquierda en armas, el apoyo estadounidense a las reformas era la demostración indiscutible de que los militares reformistas no habían roto su tradicional dependencia del imperio y daba a la lucha guerrillera el aura antiimperialista tan querida por cualquier revolucionario de la época.

\section{Apoyos y oposición interna}

Todo proceso de reforma implica procesos de apoyo y oposición internos. Podría esperarse que los apoyos provinieran de los beneficiarios y las resistencias de los afectados por las reformas, pero no siempre es así. En primer lugar, porque quienes impulsan el proyecto no siempre tienen una base social que los apoye; más bien representan pequeños grupos de militares o de la sociedad civil con una visión un tanto elitista que los lleva a autodefinirse como los llamados a liderar un proceso de transformación nacional. Y, aunque los reformistas tienden a identificar a los beneficiarios de las reformas, esto no garantiza que obtengan su apoyo; normalmente, recelos, escepticismo o impaciencia terminan reduciendo los auxilios que podrían recibirse ${ }^{10}$.

Vale decir que, en pocas ocasiones -por no decir nunca- los reformistas consultaron a los posibles beneficiarios sobre las reformas que pensaban

8 Véase Briceño Ruiz, Quintero y Ruiz de Benitez (2013) y Toye y Toye (2006).

9 Esta es la narrativa que subyace en trabajos como los de Gómez-Zimmerman (1986), Valdivieso Oriani (2008) y Panamá Sandoval (2005).

10 Un buen ejemplo de lo anterior es la manera cómo la reforma educativa de 1968 terminó fortaleciendo la organización magisterial, de la cual se nutrió la oposición a los gobiernos pecenistas (Lindo Fuentes y Ching, 2012, cap. 4). 
impulsar; a lo sumo les informaron, con lo cual se observa que, en la reforma, la tradición verticalista y autoritaria del país ha estado presente. Esto fue más evidente en la reforma agraria de los años ochenta que inició con fuertes dispositivos militares que se tomaron fincas y haciendas y luego convocaron a los campesinos beneficiarios para decirles que tenían que organizarse en cooperativas y administrar las propiedades, todo en un contexto de polarización ideológica, desconfianza, miedo y represión.

Sin embargo, más determinantes que los apoyos, han sido las oposiciones. En el siglo XIX, los grupos dominantes fueron pioneros y promotores de transformaciones, pero en el siglo XX se tornaron muy conservadores y reacios a los cambios $y$, si bien es cierto que de entre ellos surgieron fracciones progresistas, estas no tuvieron la suficiente fuerza y cohesión como para determinar el curso de los procesos. En forma general, puede decirse que, independiente del origen y las intenciones de las reformas, la resistencia a ellas ha sido muy superior a la magnitud de los cambios propuestos, como muy bien lo ejemplifica la férrea oposición del capital al proyecto de reforma agraria de mediados de los años setenta. La única excepción a esta afirmación sería el caso de las reformas contenidas en la proclama de la Fuerza Armada de octubre de 1979 e implementadas a principios de los ochenta. Considerando la magnitud de las reformas y los intereses afectados, podría aceptarse que, esta vez, la oposición de los grupos de poder económico tenía alguna justificación. En términos marxistas, este sería un caso excepcional que manifiesta la autonomía del Estado frente a las clases dominantes, ya que se impulsan cambios profundos que afectan drásticamente la base económica.

Vale la pena detenerse un poco en el proyecto de reforma agraria del gobierno de Molina para ilustrar cómo los grupos de poder económico reaccionaron en contra. Este proyecto se asocia a menudo con la guerra El Salvador-Honduras de 1969, dado que esta provocó el retorno de miles de salvadoreños, la mayoría campesinos, que fueron expulsados de Honduras, lo cual daría lugar a la necesidad de impulsar una reforma agraria. Lo cierto es que dicho conflicto solo vino a agravar un problema que ya era evidente, pero que no se quería tocar. El problema agrario comenzó a plantearse en los dos últimos años de gobierno de Sánchez Hernández; el Congreso de Reforma Agraria se realizó en 1970 y, desde un principio, quedó claro que la empresa privada no estaba de acuerdo con la iniciativa.

A pesar de esa señal poco favorable, el gobierno de Arturo Armando Molina trató de continuar con la reforma. En junio de 1975 se creó el Instituto Salvadoreño de Transformación Agraria (ISTA); un año después se decretó el Primer Proyecto de Transformación Agraria, el cual fue rechazado tajantemente por la empresa privada aglutinada en la Asociación Nacional de la Empresa Privada (ANEP) y el Frente Agrícola de las Regiones de Oriente y Occidente (FARO), al punto que el proyecto fue reformado, y prácticamente castrado, 
Ignacio Ellacuría, que siguió de cerca los eventos, consideraba que el Gobierno estaba decidido impulsar la reforma agraria, "No hay por qué dudar que el Ejecutivo deseaba poner en marcha un proceso", pero esa disposición fue insuficiente para enfrentar a la empresa privada que rechazó tajantemente la propuesta e impulsó una enorme campaña mediática en contra: "En esta campaña se utilizó la mentira, la calumnia, la amenaza, todo medio disponible, contra las autoridades del país, contra los responsables directos de la nueva orientación y, en general, contra todos aquellos que podían suponer un apoyo al cambio social" (Ellacuría, 1976, p. 637). El jesuita consideró que el Estado claudicó ante los poderes económicos. "El estrepitoso fracaso del Estado en su lucha contra los elementos más reaccionarios del capitalismo burgués ha puesto de manifiesto que estamos ante una dictadura de la burguesía, a la que el Estado no ha podido hacer frente más que durante tres meses" (Ellacuría, 1976, p. 639).

El principal obstáculo a la reforma agraria provino de la desmesurada oposición de la empresa privada, pero también de la falta de decisión de la Fuerza Armada y el PCN para defender el proyecto. A posteriori, Molina dio su versión de los hechos y trató de explicar por qué dio marcha atrás. Señala que consideró cuatro opciones: impulsar el proyecto tal y como se había aprobado, cancelarlo, modificar el proyecto y la ley del ISTA, o disolver la Asamblea y gobernar por decretos ejecutivos. Sobra decir que optó por la tercera vía: "la mejor alternativa o curso de acción era reformar los artículos del ISTA y del primer proyecto, es decir, modificar todo el plan y, por ende, aceptar su fracaso" (Molina, en Chávez Velasco, 2006, pp. 196-210). No obstante, la derrota del proyecto no se debió únicamente a la oposición del capital o a la falta de decisión del gobierno y la Fuerza Armada; el gobierno no fue capaz de generar más apoyo al proyecto entre los campesinos. Molina afirma que se reunió con los mandos militares, con los comandantes locales y que realizó "grandes concentraciones" con miembros de la Organización Democrática Nacionalista (ORDEN) y del PCN. Es decir, apeló a las bases de ORDEN y el PCN, pero no se atrevió a movilizarlas en defensa del proyecto (Chávez Velasco, 2006, pp. 193-194).

Oposición radical al proyecto por parte del gran capital, indecisión y claudicación por parte del gobierno y la Fuerza Armada, falta de apoyos decididos por parte de los campesinos, potenciales beneficiarios de la reforma y de otros sectores sociales progresistas sellaron la suerte del proyecto de reforma agraria del gobierno de Molina. En consecuencia, es posible ver este evento como un punto de inflexión que marca el agotamiento del proyecto reformista del PCN; de allí en adelante el partido no solo debió enfrentar el creciente descontento de los sectores populares, sino también el desencanto político de la oposición ante los fraudes electorales.

En la segunda mitad del siglo XX la Fuerza Armada se volvió un actor clave en la política nacional. En varias ocasiones impulsó de forma directa proyectos reformistas; en otros casos, tuvo la posibilidad de vetarlos. Así, los proyectos 
de reforma más importantes surgieron de un golpe de Estado, como sucedió en 1948, en 1962 y en 1979. El involucramiento de la institución castrense, en apariencia, garantizaba su respaldo a las reformas; sin embargo, existía una facción conservadora que intentó un contragolpe o boicoteó el proyecto reformista. Hacen falta estudios que eluciden este problema; aunque se cuenta con versiones de algunos de los participantes, su capacidad explicativa es muy limitada11. En todo caso, hay suficiente evidencia para afirmar que, desde 1931 hasta 1992, ninguna agenda de gobierno podía escapar al poder de sanción de la Fuerza Armada, convertida de facto en árbitro, en última instancia, del ejercicio del poder político en el país.

Hay que agregar que los apoyos u oposiciones a un proyecto dependen, en mucho, de la opinión pública. En este caso, el papel de los medios de comunicación, especialmente el de la prensa escrita, ha sido muy importante. En términos generales, en los medios escritos de mayor circulación ha predominado el conservadurismo; por lo tanto, tienden a rechazar las reformas, sobre todo si estas tocan los grandes intereses económicos con los que se identifican. A esa resistencia al cambio se agrega, en ocasiones, una discutible, pero políticamente funcional aura de nacionalismo y antiimperialismo que, a menudo, rodea el discurso periodístico conservador. La tónica ha sido asociar las reformas con agendas externas que atentan contra la soberanía y los intereses nacionales; sin embargo, los "intereses nacionales" se reducen a los intereses de los grupos de poder que el medio apoya.

\section{La trascendencia histórica de los proyectos de reforma}

Llegados a este punto, ya es posible hacer un balance, aunque sea preliminar, de los casos considerados. Es claro que el proyecto impulsado en las décadas de 1950 y 1960 fue el que tuvo mayor impacto social, a tal grado que muchos de sus logros en el campo económico y social todavía subsisten y otros perduran hasta la década de 1990, cuando fueron desmantelados por las reformas neoliberales. Ese impacto y permanencia se explica, ya que dichas reformas fueron producto de un proyecto construido desde diferentes instancias y madurado a lo largo de varios años. Además, este fue concebido para ampliar y fortalecer el aparato económico nacional en momentos de relativa bonanza económica y estabilidad política.

11 La narrativa de Mariano Castro Morán, un militar demócrata, cuya primera acción golpista fue en 1944 contra Hernández Martínez y que participó en muchos otros proyectos, hasta el golpe de 1979, ilustra muy bien lo señalado. Su libro cae en una especie de círculo vicioso, en el cual un grupo de militares jóvenes y demócratas dan un golpe; sin embargo, estos entregan el poder a otros que no comparten su ideal demócrata y reformista y que siempre se alinean con el capital más conservador (Castro Morán, 1987). Véase también Majano (2009) y Guerra y Guerra (2009). 
Al componente de modernización económica y estatal se agregó una apuesta por la justicia social, cuyos logros, aunque discutibles, fueron suficientemente visibles como para ganarse el apoyo de las clases sociales subalternas o, al menos, generar expectativas, con lo cual, el distanciamiento entre estas y los gobernantes fue paulatino. Cuando la crisis explotó en la segunda mitad de la década de 1970, pocos podían asociarla con el fracaso de un proyecto reformista. Además, debido, en parte, a que no se afectaron los intereses mayores del capital, la oposición conservadora no fue tan radical y decidida, quedándose más bien en la retórica sin llegar a acciones de boicot plenamente articuladas. Elementos como los enunciados favorecieron la formulación e implementación de las reformas, a tal punto que se considera que este proyecto dio lugar a un cambio de modelo de desarrollo, pasando del anterior, basado en la agroexportación, a uno que apostaba a la industrialización por sustitución de importaciones (PNUD, 2013b).

No obstante, hubo factores que actuaron en contra de la consolidación del proyecto y condujeron a su agotamiento y crisis. Por una parte, es claro que, en cierto momento, la apertura democrática se agotó; mantenerse en el poder solo sería posible mediante el fraude electoral y la represión, lo cual condujo al cierre de los espacios políticos, al desencanto y a la radicalización de la oposición. Por otra, la guerra contra Honduras no solo arruinó el MERCOMUN, sino que agudizó los problemas sociales del país, de forma específica, los relacionados con la propiedad de la tierra. La apuesta gubernamental por la reforma agraria fue pertinente a la naturaleza del problema; no así a la desmesurada oposición del capital que se mostró intransigente a cualquier propuesta, evidenciando la prepotencia y estrecha visión de los sectores más conservadores que, en última instancia, apostaron a la tradición excluyente y represiva, sin alcanzar a entender cuánto había cambiado el campesinado salvadoreño y cuán dispuesto estaba a luchar por sus demandas. En los meses que siguieron al fracaso del proyecto de Molina, campesinos organizados iniciaron una serie de "tomas de tierra" que fueron reprimidas por los cuerpos de seguridad (Chávez M., 2010, pp. 227-228).

Para 1977 era claro que el componente reformista se había diluido y solo quedaba una retórica que apelaba más a la conservación de un orden válido solo para unos pocos, pero atentatorio contra los derechos políticos y económicos de la mayoría. Tal enfriamiento de los impulsos reformistas no era nuevo. Lo novedoso consistió en la toma de conciencia por parte de los sectores sociales subalternos -especialmente campesinos- de que la raíz de sus problemas estaba en las injustas relaciones económicas, políticas y sociales a las que habían estado sometidos. La Iglesia católica - O al menos una parte de ella- jugó un papel importante en este proceso, de manera inicial, por medio de las escuelas radiofónicas y la promoción del cooperativismo y luego con las "Comunidades Eclesiales de 
Base", en una vertiente ligada a la Teología de la Liberación (Cabarrús, 1983, pp. 140-160; Almeida, 2011, pp. 140-144 y Chávez M., 2010, pp. 131-144)².

Sin embargo, el proyecto reformista más trascendental, en términos de lo que pudo significar, es el de 1979, no solo porque, como se señaló, pretendía transformaciones drásticas y profundas, sino porque su éxito pudo haber reducido la explosiva conflictividad política que entonces se vivía. Resulta, entonces, una lástima que la intransigencia y radicalidad de las extremas lo anularon en el ámbito político. La derecha estaba dispuesta a todo con tal de bloquear las reformas, primeras en la historia republicana, que afectaban sus intereses económicos. Pero también es importante mencionar que la intransigencia de la izquierda radical, entusiasmada en su agenda revolucionaria a raíz del triunfo de los sandinistas en Nicaragua, contribuyó -y no poco- a ahogar un proceso que pudo haber ahorrado ingentes costos humanos y materiales. En este sentido, si se observan con detenimiento los hechos -y acotando el análisis al problema de "reforma o revolución"- se puede argumentar que la derecha actuaba con base en constataciones, mientras que la izquierda con base en meras expectativas.

Empero, no puede obviarse en este análisis el conflicto de la represión y el brutal accionar de los Escuadrones de la Muerte después del golpe de Estado, los cuales dieron razones adicionales a la izquierda para radicalizarse. En este punto, la mayor responsabilidad recae en la Fuerza Armada. La falta de liderazgo, decisión y compromiso con el proyecto, así como las divisiones al interior del ejército, debilitaron el componente reformista y reforzaron la tradicional línea conservadora castrense, lo que favoreció a las fuerzas de derecha más recalcitrantes.

Para Monseñor Óscar Arnulfo Romero, a inicios de la década de 1980, en El Salvador, se enfrentaban tres "proyectos económico-políticos": uno oligárquico, que "pretende impedir que se lleven adelante reformas estructurales que afectan sus intereses pero favorecen a la mayoría de los salvadoreños". El segundo proyecto era el gubernamental, impulsado por la Fuerza Armada y el Partido Demócrata Cristiano (PDC), con una aparente tendencia "popular antioligárquica" y que impulsaba una serie de reformas estructurales, pero que "ha sido incapaz de aglutinar a los sectores, organizaciones populares, y se ha dedicado más bien a reprimir y masacrar en forma indiscriminada y desproporcionadamente a los campesinos y otros sectores del pueblo". Por último, se refería al proyecto de las "organizaciones populares y político-militares", que percibía en proceso de unificación con miras a formar "una amplia y poderosa unidad de fuerzas revolucionarias y democráticas" (Cardenal et al., 1986, pp. 237-238) ${ }^{13}$. A este último, Romero le había cuestionado en varias ocasiones su radicalismo en lo que él llamaba "absolutización del poder", que tendía a hacer del tema

12 Para una versión testimonial de este proceso, véase el documental de Consalvi Henríquez y Gould (2011). 13 Monseñor Óscar A. Romero. Homilía del 20 de enero de 1980. 
político, en especial "la toma del poder" y la revolución el centro de la vida individual o grupal (Cardenal, et al., 1986, p. 149)14.

En su homilía del 20 de enero de 1980, Romero dejó bien clara su posición respecto a estas aspiraciones. Rechazaba el proyecto oligárquico porque solo trataba de defender tanto privilegios como riqueza. Se negaba a compartir, señalaba que esa intransigencia alejaba cada vez más "la posibilidad de resolver la crisis estructural de forma pacífica". Del proyecto gubernamental aceptaba la pertinencia de las reformas en marcha, pero rechazaba el uso excesivo de la violencia, "no puede estabilizarse jamás un Gobierno que, junto a sus promesas de cambio y justicia social" reprime a la oposición. Por último, pedía al proyecto de las organizaciones de izquierda que construyera una amplia unidad que buscara el bien del país y "trate de evitar al máximo la violencia, la venganza y todas esas actividades que extienden o intensifican el derramamiento de sangre" (Cardenal, et al., 1986, pp. 238-239) ${ }^{15}$.

En dicha homilía, Monseñor Romero mostraba, de forma dramática, el escenario en que se montaba la tragedia de la década de 1980, a la cual solo le faltaban detalles de coreografía. Las reformas eran rechazadas por la izquierda y la derecha más radicales. Extraña situación radica en que los opuestos confluyen, aunque lo hicieran por diferentes razones. Romero no cuestiona la necesidad de hacer las reformas, lo que no acepta es la incapacidad del gobierno para controlar a las fuerzas represivas y reaccionarias, enquistadas dentro del aparato estatal o ligadas a estructuras paramilitares, que reprimen, desaparecen o asesinan a miembros de la oposición, de las organizaciones populares, de la guerrilla o a cualquier sospechoso de ser militante o simpatizante de ellas. La izquierda actuaba en consecuencia, y ponía de su parte. El análisis de Monseñor Romero muestra la extrema polarización político-ideológica que vivía el país, de la cual él sería víctima unos meses después. Su asesinato vino a confirmar que la sinrazón y el fanatismo habían ganado la partida. El telón estaba por correrse.

Para 1981, izquierda y derecha radicales (dentro de esta se incluye a la Fuerza Armada) apostaron por la derrota de su contrario. Es probable que en ambos bandos hubo convicción y determinación, al igual que soberbia y falta de visión. Luego de una década de ingentes esfuerzos, con costos económicos y humanos altísimos para el tamaño del país, aceptaron que ninguno podía derrotar al otro y debieron transigir en la mesa de negociación. Un empecinamiento en las agendas unilaterales solo hubiese prolongado el conflicto. Como bien dijo Salvador Samayoa, el Acuerdo de Paz fue una "reforma pactada", en la cual cada bando consiguió algo, a costa de ceder algo (Samayoa, 2003).

14 Monseñor Óscar A. Romero. Cuarta carta pastoral, seis de agosto de 1979.

15 Monseñor Óscar A. Romero, Homilía del 20 de enero de 1980. 
El Acuerdo de paz dio lugar a una transformación del país, al menos en términos de democratización, creación o rediseño de instituciones, libertades políticas, respeto a los derechos humanos y, sobre todo, en la vía de no permitir más la injerencia de la Fuerza Armada en los procesos políticos (El Salvador: los acuerdos de paz y el informe de la Comisión de la Verdad, 2007). Sin embargo, dichos cambios no fueron suficientes, comparados con lo que se intentó en 1979 y que, con tanta obstinación, rechazaron las extremas. Despúes de 13 años, al firmar el Acuerdo de Paz, derecha e izquierda aceptaban que no supieron o quisieron dar a ese proyecto la oportunidad que merecía. Aún hoy, no se alcanza a dimensionar el costo de esa intransigencia.

\section{Epílogo}

Lo dicho hasta aquí da pie para hacer algunas reflexiones generales sobre las experiencias reformistas en El Salvador. En apariencia, la mayor ventaja de un proyecto de reforma radica en que no pretende hacer tabula rasa de lo existente, sino mejorarlo para tener optimas posibilidades de desarrollo. Por lo mismo, es plausible esperar que logre convocar el apoyo de buena parte de la población, sin importar que las extremas lo vean con recelo. Sin embargo, un programa de reformas siempre está expuesto a la impaciencia de los sectores sociales menos favorecidos y a la resistencia de aquellos que consideran que los cambios amenazan sus intereses o cuestionan los valores que históricamente han sostenido. Por lo tanto, la mayor dificultad consiste en la sostenibilidad del proceso, de tal modo que puedan evidenciarse los beneficios de los cambios sin que los intereses de los grupos dominantes se vean menoscabados. El gran reto es mantener en marcha las reformas, sin que parezcan desmesuradas o insuficientes.

No obstante, resulta más asequible que los sectores conservadores reaccionen en contra del proyecto, que lograr que los supuestos beneficiarios de este se entusiasmen con él y lo defiendan. Y es que es más fácil convencer a las masas de luchar por la revolución o defender un "sistema" amenazado, que persuadirlas de defender un "programa de reformas". Las reformas no son heroicas, no son temas épicos. Las reformas llaman a la razón, pero no provocan pasión.

Un proceso de reforma, cuando realmente lo es, enfrentará múltiples escollos que demandarán de sus impulsores cualidades y habilidades políticas diversas. A veces tendrán que ser cautos y condescendientes, para no provocar asperezas y recelos innecesarios en los grupos de poder; otras, deberán ser audaces y decididos, pues solo así tendrán el apoyo de los sectores a quienes pretenden beneficiar. Todo esto sin olvidar que el punto de equilibrio se rompe fácilmente, ya que cualquier acción podría ser interpretada como inaceptable señal de radicalización o claudicación. 
Las reformas son necesarias, pero pocas veces resultan atractivas, más allá de los círculos que las conciben e impulsan. En general, sus resultados son mucho más modestos de lo previsto cuando se formulan, y pocas veces dejan satisfechos a promotores y receptores. Sin embargo, no se debiera olvidar su principal virtud: asumir que es posible resolver los problemas sin anular o desmantelar lo positivo ya existente. Pero quizá, más importante, las reformas permiten no solo el remozamiento de las esperanzas de los sectores sociales menos favorecidos, sino su satisfacción gradual, sin hipotecar el futuro del país y las libertades ciudadanas en proyectos más radicales y más atractivos, pero en los que reaparece la tentación autoritaria, aunque sea de signo ideológico distinto.

En El Salvador, el siglo XX estuvo marcado por las reformas o los intentos de reforma. Puede afirmarse, aunque solo sea para provocar el debate, que el país inició el siglo con un proyecto de reforma abortado, el de Manuel Enrique Araujo. En el otro extremo del arco temporal, la guerra civil se debió, en buena medida, a la postergación, insuficiencia y deslegitimación de las reformas finalmente impulsadas a inicios de la década de 1980, pero concebidas y, sobre todo, demandadas desde varios lustros antes. En tal perspectiva, las reformas estarían en la génesis de la guerra civil; no es extraño, entonces, que el conflicto finalizara por la vía de las reformas, que no otra cosa fue el Acuerdo de Paz de 1992.

Si se retoma la propuesta de Hobsbawm de un "siglo XX corto" (1998), en El Salvador, este iría de 1911 a 1992: apenas 81 años; no obstante, repletos de historia, tanta que aún no se alcanza a dimensionar cuántos sueños y frustraciones, cuánto drama y tragedia llevaron consigo, pero, sobre todo, cuántas oportunidades se perdieron por no entender que crecimiento económico no significa desarrollo. Hizo falta audacia y decisión para impulsar los cambios necesarios en los momentos oportunos; también faltó humildad para aceptar que la riqueza o las ideas políticas no son valores absolutos, y que la persona humana vale mucho más que ellas.

El siglo XX comenzó y finalizó bajo el signo de las reformas, sin que hayan sido estudiadas, entendidas y valoradas de la forma adecuada. Si así se hiciera, podría encontrarse que mucho de lo positivo y negativo del periodo provino precisamente del éxito o fracaso de los proyectos reformistas. Por ejemplo, los endebles rasgos de Estado de bienestar que El Salvador tuvo, y los pocos que aún conserva, tuvieron su origen en el ambicioso proyecto de reformas de las décadas de 1950 y 1960 ; por el contrario, la tragedia de la guerra civil no puede desligarse de la postergación y posterior boicot y fracaso de las reformas.

Ya en la posguerra y durante los cuatro gobiernos de ARENA, la derecha descalificó las aspiraciones del FMLN de llegar al poder por la vía electoral, haciendo alusión a su pasado guerrillero, y advirtiendo que, de lograrlo, el Frente usaría el poder ejecutivo como trampolín para llevar al país hacia el modelo socialista. En otras palabras, haría por la vía democrática lo que no pudo hacer por la vía 
armada. Ya ha habido dos gobiernos de izquierda y nada de eso ha acontecido; podrán discutirse las razones, pero la evidencia demuestra que el FMLN ha trabajado no en la línea revolucionaria, sino en la reformista, especialmente en lo que a políticas sociales se refiere. Resulta obvio que esta opción ha desencantado a algunos, quienes esperaban tendencias más radicales, pero también ha aplacado dudas en otros, quienes temían una gestión más intrépida. Pareciera que la experiencia histórica ha demostrado a la izquierda que las reformas no deben rechazarse a priori; ojalá también lo haya aprendido la derecha.

\section{Referencias}

Almeida, Paul. (2011). Olas de movilización popular: Movimientos sociales en El Salvador, 1925-2010. San Salvador: UCA Editores.

Alvarenga, Patricia. (1996). Cultura y ética de la violencia. El Salvador 18801932. San José: Editorial Universitaria Centroamericana [EDUCA].

Anderson, Thomas. (1982). El Salvador. Los sucesos políticos de 1932. San José: Editorial Universitaria Centroamericana [EDUCA].

Bobbio, Norberto, Matteucci, Nicola y Pasquino, Gianfranco. (1978). Diccionario de política. México, D.F.: Siglo XXI Editores.

Briceño Ruiz, José, Quintero, María lleana y Ruiz de Benítez, Dyanna. (2013). El pensamiento estructuralista de la CEPAL sobre el desarrollo y la integración latinoamericana: reflexiones sobre su vigencia actual. Revista Aportes para la Integración Latinoamericana, XIX(28), 1-34.

Browning, David. (1998). El Salvador, la tierra y el hombre. San Salvador: Dirección de Publicaciones e Impresos.

Bulmer Thomas, Victor. (1989). La economía política de Centroamérica desde 1920. San José: Banco Centroamericano de Integración Ecónica [BCIE]Editorial Universitaria Centroamericana [EDUCA].

Cabarrús, Carlos Rafael. (1983). Génesis de una Revolución. Análisis del surgimiento y desarrollo de la organización campesina en El Salvador. México: Ediciones de la Casa Chata.

Cáceres Prendes, Jorge. (1995). Discourses of Reformism: El Salvador, 19441960. Tesis doctoral, University of Texas, Texas.

Cardenal, R., et al. (Eds.). (1986). La voz de los sin voz. La palabra viva de Monseñor Óscar Arnulfo Romero. San Salvador: UCA Editores.

Castro Morán, Mariano. (1987). Función política del ejército salvadoreño en el presente siglo. San Salvador: UCA Editores. 
Chasteen, John C. (1984). Manuel Enrique Araujo and the Failure of Reform in El Salvador, 1911-1913. South-eastern Latin Americanist, (2), 1-16.

Chávez M., J. (2010). The Pedagogy of Revolution: Popular Intellectuals and the Origins of the Salvadorean Insurgency, 1960-1980. Tesis doctoral, New York University, New York.

Chávez Velasco, Waldo. (2006). Lo que no conté sobre los presidentes militares. San Salvador: Índole Editores.

Ching, Erik. (1997). From Clientelism to Militarism: The State, Politics and Autoritarism in El Salvador, 1840-1940. Tesis doctoral, University of California, Santa Bárbara.

Ching, Erik. (2013). Authoritarian El Salvador. Politics and the Origins of the Military Regimes, 1840-1940. Notre Dame: University of Notre Dame Press.

Ching, Erik, López Bernal, Carlos Gregorio y Tilley, Virginia. (2007). Las masas, la matanza y el martinato en El Salvador. San Salvador: UCA Editores.

Consalvi Henríquez, Carlos y Gould, Jeffrey (Dirs). (2011). La palabra en el bosque [Documental]. El Salvador: Museo de la Palabra y la imagen.

Dada Hirezi, Héctor. (1978). La economía de El Salvador y la integración centroamericana, 1945-1960. San Salvador: UCA Editores.

El Salvador: Ios acuerdos de paz y el informe de la Comisión de la Verdad. (2007). San Salvador: Editorial Nuevo Enfoque.

Ellacuría, Ignacio. (1976). A sus órdenes, mi capital. ECA Estudios Centroamericanos, XXXI (337), 636-643.

Gómez-Zimmerman, Mario. (1986). El Salvador: la otra cara de la guerra. Miami: Editorial SIBI.

González Márquez, Luis Rubén. (2016). Política popular contenciosa: movilización social y hegemonía en El Salvador, 1919-1932. Tesis de maestría, Facultad Latinoamericana de Ciencias Sociales, Ecuador, Quito.

Guerra y Guerra, Rodrigo. (2009). Un golpe al amanecer. San Salvador: Índole Editores.

Guidos Véjar, Rafael. (1980). Ascenso del militarismo en El Salvador. San Salvador: UCA Editores.

Hobsbawm, Eric. (1998). Historia del siglo XX. Buenos Aires: Crítica.

Kincaid, Douglas. (1987). Peasants into Rebels: Community and Class in Rural El Salvador. Comparative Studies in Society and History, 29(3), 466-494. 
Lauria Santiago, Aldo. (1999). An Agrarian Republic. Commercial Agriculture and the Politics of Peasant Communities in El Salvador, 1823-1914. Pittsburgh: University of Pittsburgh Press.

Lindo Fuentes, Héctor. (1990). Weak Foundations. The Economy of El Salvador in the Nineteenth Century. Berkeley: University of California Press.

Lindo Fuentes, Héctor y Ching, Eric. (2012). Modernizing Minds in El Salvador. Education Reform and the Cold War, 1960-1980. Albuquerque: University of New Mexico Press.

López Bernal, Carlos Gregorio. (2000). Años de bonanza y crisis; de ilusiones y desencantos. 1924-1931. En Álvaro Magaña (Ed.), El Salvador; la república (pp. 45-90). San Salvador: Fomento Cultural, Banco Agrícola.

Majano, Adolfo. (2009). Una oportunidad perdida: 15 de octubre 1979. San Salvador: Índole Editores.

Martín Álvarez, Álvaro. (2005). De movimiento de liberación a partido político. Articulación de los fines organizativos en el FMLN salvadoreño (1980-1992). Tesis doctoral, Universidad Complutense de Madrid, Madrid.

Menjívar, Rafael. (1979). Formación y lucha del proletariado industrial salvadoreño. San Salvador: UCA Editores.

Menjívar, Rafael. (1980). Acumulación originaria y desarrollo del capitalismo en El Salvador. San José: Editorial Universitaria Centroamericana [EDUCA].

Molina, Walter René. (2015). El Salvador (1927-1930), del semiautoritarismo a la semidemocracia: Elecciones, protestas y libertad de prensa. Tesis de maestría, Universidad Autónoma del Estado de México, Toluca.

Paige, Jeffery. (1993). Coffe and Power in El Salvador. Latin American Research Review, 28(3), 7-40.

Panamá Sandoval, David Ernesto (2005). Los guerreros de la libertad. Andover, MA: Versal Books.

Paredes, Jacinto. (1930). Vida y obras del doctor Pío Romero Bosque; apuntes para la historia de El Salvador. San Salvador: Imprenta Nacional.

Parkmam, Patricia. (2003). Insurrección no violenta en El Salvador. San Salvador: Dirección de Publicaciones e Impresos.

Programa de las Naciones Unidas para el Desarrollo [PNUD]. (2013a). Informe de Desarrollo Humano. El Salvador 2013. San Salvador: Programa de las Naciones Unidas para el Desarrollo. 
PNUD. (2013b). Informe sobre desarrollo humano. El Salvador 2013. San Salvador: PNUD Programa El Salvador.

Samayoa, Salvador. (2003). El Salvador: la reforma pactada. San Salvador: UCA Editores.

Sprenkels, Ralph. (2014). Las relaciones urbano-rurales en la insurgencia salvadoreña. En Jorge Juárez Ávila (Ed.), Historia y debates sobre el conflicto armado salvadoreño y sus secuelas (pp. 25-43). San Salvador: Instituto de Estudios Históricos, Antropológicos y Arqueológicos /Fundación Friedrich Ebert.

Torres Rivas, Edelberto. (2013). Revoluciones sin cambios revolucionarios. Ensayos sobre la crisis en Centroamérica. Guatemala: F \& G Editores.

Toye, John y Toye, Richard. (2006). Raúl Prebisch y los límites de la industrialización. En Susana Filippa (Ed.), Raúl Prebisch. El poder, los principios yla ética del desarrollo (pp. 23-32). Buenos Aires: BID-INTAL.

Turcios, Roberto. (2003 [1993]). Autoritarismo y modernización: El Salvador 1950-1960. San Salvador: Dirección de Publicaciones e Impresos.

Valdivieso Oriani, Ricardo Orlando (2008). Cruzando El Imposible: una saga. San Salvador: Imprenta Wilbot.

Walter Franklin, Knut. (2001a). Ideales igualitarios y autodeterminación. 19611972. En ÁlvaroMagaña (Ed.), El Salvador. La República (Vol. II, pp. 468499). San Salvador: Fomento Cultural, Banco Agrícola.

Walter Franklin, Knut. (2001b). La apropiación de las verdades, 1979-1989. En A. Magaña (ed.), El Salvador. La república (Vol. II, pp. 566-599). San Salvador: Fomento Cultural Banco Agrícola.

Wilson, Everett Alan. (2004). La crisis de la integración nacional en El Salvador, 1919-1935. San Salvador: Dirección de Publicaciones e Impresos. 